\title{
The Effect of Mindfulness Techniques on Teacher Resilience as Moderated by Conscientiousness
}

\author{
Aundrea T. Harris, $\mathrm{PhD}$ \\ Walden University, Minneapolis, Minnesota, United States \\ iD https://orcid.org/0000-0002-0520-1800 \\ Nancy S. Bostain, PhD \\ Walden University, Minneapolis, Minnesota, United States \\ (iD https://orcid.org/ 0000-0001-6150-6310
}

Contact: aundrea.harris@mail.waldenu.edu

\section{Abstract}

Burnout continues to be apparent among teachers and often leads to increased health care costs, absenteeism, and turnover rates. Burnout stems from unmanaged stress, which is the result of teachers' response to challenges in the workplace. The purpose of this cross-sectional design study was to examine the relationship between mindfulness techniques and resilience in high school teachers. An additional purpose was to examine whether the personality trait and conscientiousness moderate the relationship between mindfulness techniques and resilience. The frameworks for this study were based on the self-awareness, -regulation, and transcendence (S-ART) framework, the theory of planned behavior, and the concepts of resilience and job burnout. Four surveys were used to gather data from 133 high school teachers to understand the relationship between mindfulness techniques and resilience as well as how conscientiousness moderates the relationship. Multiple regression analysis was used to analyze the data. This study found a significant relationship between mindfulness techniques and resilience in high school teachers. Additionally, this study found that conscientiousness does not significantly moderate the relationship between mindfulness techniques and resilience in high school teachers. These results might be used to create a professional development tool for teachers to help them learn how to increase the quality of classroom interactions and their resilience through the use of mindfulness techniques. The outcome may be a more positive social and academic environment for students as well as teachers, based on the encouraged use of mindfulness techniques.

Keywords: teacher burnout; resilience; mindfulness techniques; conscientiousness

Date Submitted: August 4, 2020 | Date Published: April 22, 2021

\section{Recommended Citation}

Harris, A., \& Bostain, N. (2021). The effect of mindfulness techniques on teacher resilience as moderated by conscientiousness. Journal of Educational Research and Practice, 11, 81-94.

https://doi.org/10.5590/JERAP.2021.11.1.06

\section{Introduction}

The rate that teachers are leaving the education system is gradually increasing (Flook et al., 2013; McCormick \& Barnett, 2011) due to burnout (Jennings et al., 2017; Roeser et al., 2012). Burnout continues to be apparent 
among teachers and often leads to increased health care costs, absenteeism, and turnover rates. Burnout stems from unmanaged stress, which is the result of teachers' response to challenges in the workplace. However, increasing resilience levels in teachers is an option for reducing the risk of burnout among teachers (Montero-Marin et al., 2015; Olson et al., 2015). The use of mindfulness techniques lowers the risk of burnout and increases resilience (Flook et al., 2013; Olson et al., 2015). Additionally, mindfulness helps to reduce stress, promotes self-awareness and self-regulation, and helps individuals navigate through challenging moments. Mindfulness also encourages collaboration in the classroom between teachers and students. Therefore, the primary hypothesis of the study was that high school teachers' use of mindfulness techniques would significantly predict their resilience. It was hypothesized that conscientiousness would moderate the relationship between using mindfulness techniques and resilience.

\section{Definition of Key Terms}

Burnout: The occurrence of constant job stress resulting in emotional fatigue concerning a psychological condition of depersonalization and reduced personal success with service providers (Maslach et al., 1993; Maslach, 1998; Maslach et al., 2001).

Conscientiousness: An individual's personality of will and discipline to accomplish goals (Digman, 1990; George \& Zhou, 2001; Roberts et al., 2014). The trait of diligence, success focus, and perseverance during adverse situations (Barrick \& Mount, 1991).

Mindfulness: A purposeful experience of the present moment without making any judgments or decisions about it (Kabat-Zinn, 2012).

Resilience: The capacity to manage stress in a successful way (Campbell-Sills \& Stein, 2007).

Teacher resilience: The capacity of teachers to endure environmental stressors while maintaining their teaching responsibility (Mansfield et al., 2012).

\section{Literature Review}

According to the self-awareness, -regulation, and -transcendence (S-ART) framework, a person's awareness, thoughts, and feelings connected to their daily experiences can be distorted to a certain extent (Vago \& Silbersweig, 2012). But when people use mindfulness techniques consistently, they could reduce bias about themselves and increase their awareness about well-being (Good et al., 2016; Purser \& Milillo, 2015). The use of mindfulness techniques might be a way to reduce burnout and encourage wellness among teachers as well as encourage self-awareness and self-regulation (Jennings et al., 2013; Vago \& Silbersweig, 2012).

First identified as a social problem, burnout is considered a state of emotional fatigue, depersonalization, and condensed personal success that can happen among people who do public work of some kind (Maslach et al., 1993; Maslach, 1998; Maslach et al., 2001; McCormick \& Barnett, 2011). Stress occurs when there is a gap in work demands and an individual's perceived ability to meet those demands (Roeser et al., 2012; McCarthy et al., 2009). Unresolved stress often triggers burnout (Maslach et al., 2001), which can result in a decline in the quality of care or service provided and could be a reason for job turnover, absenteeism, and low morale (Leiter \& Maslach, 2016; Maslach et al., 1993; Maslach et al., 2001). Burnout is an occupational hazard for professions focused on people, such as education, human services, and healthcare, as it can weaken an individual's personal and social functioning (Maslach, 1998). Burnout can also lead to a decline in quality of work and physical and psychological health, which can be costly (Maslach, 1998). However, individuals can reduce their risk of burnout by managing the demands of their workplace (Maslach et al., 2001). Additionally, 
mindfulness is a technique that has been positively related to resilience and inversely related to burnout (Olson et al., 2015).

Resilience is known as inward inspired energy that guides an individual toward self-actualization, selflessness, and assistance in coping with change or adversity (Campbell-Sills \& Stein, 2007; Ledesma, 2014; Richardson, 2002; Yates \& Masten, 2004). Each person has the potential to grow resilience through their qualities and strengths. There are many attributes individuals have that help them to be resilient in challenging situations. For example, in a 30-year longitudinal study of a multiracial population of children, 72 of 200 children did fine in the face of adversity because of several resilient characteristics such as being socially responsible, adaptable, tolerant, and good at communicating, as well as having self-mastery and self-efficacy (Richardson, 2002). Resilience is necessary for building a defense against chronic stress to improve the well-being of teachers (Arcelay-Rojas, 2019). Resilient people have a distinct ability to help themselves endure adverse situations (Campbell-Sills \& Stein, 2007; Richardson, 2002). There is also a strong connection between mindfulness and resilience (Kemper et al., 2015; Meiklejohn et al., 2012; Montero-Marin et al., 2015; Olson et al., 2015). For example, Aikens et al. (2014) indicated that those involved in mindfulness interventions increased mindfulness, resiliency, and vigor.

As a technique for improving resilience, mindfulness involves having a calm understanding and openness to the present moment and experience (Brown \& Ryan, 2003; Kabat-Zinn, 2012; Marx \& Jones, 2017; Napoli, 2004). Mindfulness is when a person takes care of his or her consciousness by keeping it active in the present moment (Nhất Hạnh, 1987). Amid adversity, people can use mindfulness to help them be aware of what is going on and prepared to handle the situation well. Mindfulness builds a life of awareness, moving a person from inattentiveness to attentiveness. Mindfulness can also be defined using three significant words: intention, attention, and attitude-an individual's purpose of thoughts and approach about it (Kabat-Zinn, 2012). When people consistently use mindfulness, they might become more intentional about their thoughts.

Mindfulness has been regarded as a method for stress reduction, self-awareness, and self-regulation (Jennings et al., 2017; Marianetti \& Passmore, 2012; Marx \& Jones, 2017). Being a habit of mind, mindfulness has been viewed as a protective factor to prevent high levels of burnout (Piatkowska, 2014; Roeser et al., 2012). Mindfulness can be conceived and measured as both a trait and state (Sutcliffe et al., 2016), which can be examined by questionnaires and influence the health of human beings (Montero-Marin et al., 2015). A person can develop their skill of mindfulness through continuous practice (Kabat-Zinn, 2012), which helps to build resilience and results in reducing risks connected with stress (Pierotti \& Remer, 2017). Thus, mindfulness is a reliable and valid measured characteristic that plays a vital part in promoting well-being and mental health (Brown \& Ryan, 2003).

The use of mindfulness tools has many benefits for teachers in their workplace. Two advantages of mindfulness are stress reduction and decreased burnout levels. Stress can influence a teacher's capability to be receptive and efficient in the classroom. The appearance of stress can be reflected in "time demands, workload, student disruptive behavior, and organizational factors" (Flook et al., 2013, p. 5). In a study conducted by Piatkowska (2014), the association between mindfulness and burnout was examined with the Five-Facet Mindfulness Questionnaire (FFMQ) to test the hypothesis of mindfulness being a solution to lower burnout levels. The results indicated that mindfulness could assist as protection against high levels of burnout. Additionally, Flook et al. (2013) conducted a pilot study of a revised mindfulness-based stress reduction training for elementary school teachers who served mainly low-income and ethnic-minority residents and found that mindfulness intervention for teachers will help to alleviate burnout and psychological symptoms, improve teaching behavior influence, and diminish attentional biases. Research has also shown that during the first year of experiencing mindfulness, teachers have reported that their well-being improved, their stress decreased, and they gave more attention to lesson plans and students (Bernay, 2014). 
Further, there is a positive connection between mindfulness and conscientiousness (Crescentini \& Capurso, 2015; Giluk, 2009; Latzman \& Masuda, 2013; Lee \& Bowen, 2014; Siegling \& Petrides, 2014).

Conscientiousness is a thought-provoking factor for those interested in living a lengthy, healthy, productive, and happy life (Roberts et al., 2014). Conscientiousness is most noted as a personality trait that identifies the instinctive thoughts, feelings, and behaviors that distinguish individuals from each other (George \& Zhou, 2001; Roberts et al., 2005, 2014). Conscientiousness is natural as well as influenced by the environment, meaning it is changeable and can be developed (Roberts et al., 2005, 2014). For instance, De Vibe et al. (2015) collected data before and after a mindfulness intervention to examine if personality traits influenced the use of mindfulness and found that mindfulness had a significant effect on the participants displaying high conscientiousness and neuroticism scores. Because conscientiousness is one of the strongest predictors of many work outcomes, such as performance, it should be given more thought in research with mindfulness, especially with research in the workplace (Giluk, 2009). For example, Sesker et al. (2016) conducted a study with 602 participants and suggested conscientious individuals often seem to be healthier physically and mentally (Sesker et al., 2016). However, more research is needed to expand on conscientiousness and stress resilience (Sesker et al., 2016).

\section{Participants and Procedure}

For this quantitative study, high school teachers were the target population. There were 245 high school teachers from three public schools invited to participate in this study. A power analysis was used to determine the sample size needed to have sufficient power to detect statistical analysis. The power analysis suggested a sample size of 92 high school teachers. To increase generalizability, we needed to increase the sample size to 151 high school teachers. The final sample was 156 teachers who participated in the research.

An email was sent to all three public high school administrators to distribute the survey to their high school teachers. The link to the survey was in the email and directed each high school teacher to Survey Monkey. When the high school teachers accessed the link, an informed consent form was provided. After providing consent to participate in the study, the high school teachers were directed to the survey. The survey was composed of four different surveys: FFMQ, Connor-Davidson Resilience Scale (CD-RISC), Big Five Aspects Scale (BFAS): Conscientiousness, and Maslach Burnout Inventory (MBI)-Educator Survey. The estimated time for the high school teachers to complete the survey was 20 to 30 minutes. The high school teachers were asked to complete the survey one time.

\section{Measures}

\section{Five-Facet Mindfulness Questionnaire}

The FFMQ is a self-report questionnaire with 39 items that measure mindfulness (Baer et al., 2008). There are five mindfulness attributes measured through subscales: acting with awareness, describing, observing/noticing, nonreactivity to inner experience, and nonjudging of inner experience (Aikens et al., 2014; Baer et al., 2006; Williams et al., 2014). The five subscales are combined to produce a total score to reflect a global measure of mindfulness. High levels of mindfulness are quantified by a high total score (Williams et al., 2014). Researchers have supported the validity of the FFMQ (Aguado et al., 2015; Baer et al., 2008; de Bruin et al., 2012). The FFMQ has adequate reliability, convergent and discriminant validity, and incremental validity in the prediction of psychological symptoms (Baer et al., 2008). Williams et al. (2014) also found that the FFMQ showed internal consistency where Cronbach's alphas were between .77 and .93 (see also Baer et al., 2008). However, researchers should be careful about using the FFMQ to measure mindfulness to relate meditator and nonmeditator samples unless the observing/noticing facet is omitted (Williams et al., 2014). Further, Aguado et al. (2015) calculated the reliability ( $\omega=0.93$ ), which provided support for reviewing each factor of the FFMQ rather than as a single score. In this study, we measured the FFMQ subscales rather than a combined score of each scale. Each factor showed reliability: observing (0.85), 
describing (0.90), acting with awareness (0.91), nonjudging of inner experience (0.92), and nonjudging to inner experience (o.82). These results were similar to the alpha coefficients in a study conducted with nonmeditating and meditating samples (de Bruin et al., 2012).

\section{Connor-Davidson Resilience Scale}

The CD-RISC is a self-reporting survey with 25 items that measure resilience (Connor \& Davidson, 2003). The total score ranges from o to 100; greater resilience is specified by a high score (Connor \& Davidson, 2003). The psychometric properties of the CD-RISC demonstrate test-retest reliability and good internal consistency showing Cronbach's alpha $=.89$ (Connor \& Davidson, 2003).

\section{Big Five Aspects Scale: Conscientiousness}

The BFAS: Conscientiousness measures personality traits based on the Big Five factor markers (Goldberg, 1999). For this study, the conscientiousness domain was evaluated, consisting of 20 items (Goldberg, 1999). The BFAS: Conscientiousness has been validated as a reliable and valid instrument to measure personality traits (Goldberg et al., 2006; Topolewska et al., 2017). The coefficient alpha for the BFAS: Conscientiousness is .84 for the conscientiousness domain (Goldberg, 1999).

\section{Maslach Burnout Inventory-Educator Survey}

The MBI-Educator Survey is a self-reporting survey with 22 items to measure burnout. Three scales measure emotional exhaustion, depersonalization, and personal accomplishments (Maslach et al., 1993; Maslach et al., 1996; Maslach et al., 2019). A single score is not produced (Kokkinos, 2006). A high level of burnout is determined by a high score of emotional exhaustion and depersonalization and a low score of personal accomplishment (Kokkinos, 2006). There were two studies with teachers that established the reliability of the MBI-Educator Survey. Factor analysis showed a three-factor structure and internal reliability (Maslach et al., 1996). Cronbach's alphas were emotional exhaustion (.90 and .88), depersonalization (.76 and .74), and personal accomplishment (.76 and .72; Maslach et al., 1996). Maslach et al. (1996) suggested that the reliabilities of the MBI-Educator Survey are equivalent to the original MBI.

\section{Data Analysis}

To begin the analysis, we completed data cleaning and screening. A total of 358 people attempted to access the online survey. Of these, 37 did not meet the criteria, and 102 did not consent to the survey. These 139 surveys were removed from the dataset, leaving 219 surveys. The surveys were assessed for completion of at least $90 \%$. Of the 219 surveys, 39 were missing more than $90 \%$ of the data and were deleted, leaving 180 surveys.

Twenty-four surveys had less than three missing answers and were assigned the average response of all the other participants who completed the survey (grand mean). The data collection process yielded 156 completed surveys from high school teachers.

Boxplots were conducted, and 22 univariate outliers were detected and removed, leaving 134 surveys. Next, a Mahalanobis Distance Test was conducted to identify the presence of multivariate outliers, and one multivariate outlier was detected and removed. The final sample size for this study was $N=133$. The normality of the criterion variable (resilience) was deemed adequate based on a boxplot and a frequency histogram. We examined bivariate normality using bivariate scatterplots and Pearson correlations between each of the predictor variables and the criterion variable. All the mindfulness scores and conscientiousness were related to resilience.

Independence of errors was not a problem due to the design of the study (each person only completed one survey), and the Durbin-Watson statistics were within normal limits. Multicollinearity was not found based 
on variance inflation factor and tolerance statistics. We created regression assumption plots (residual histogram, residual P-P plots, a scatterplot of regression standardized residuals against the regression standardized predicted values) for all regression models and found homoscedasticity assumptions had been adequately met. Taken together, along with the generally robust nature of the general linear model in larger samples ( $\mathrm{N}=133$; see Vogt, 2011), the assumptions for Pearson correlations and multiple regression were adequately met.

\section{Ethical Procedures}

There were no risks or conflicts for participants or stakeholders regarding this study. Guidelines were followed to minimize risks and conflict of interest and protect participants' and stakeholders' welfare. Data collection was held with integrity and confidentiality. After organizing the data in an Excel spreadsheet and checking that all questions were answered, we deleted the surveys from Survey Monkey. The data collected were stored on a USB drive with password protection and placed in a locked file cabinet. The plan to collect data anonymously was to design the consent and data collection procedures so that identities were completely protected.

\section{Findings}

Burnout is constant among teachers, and resilience improvement might lower the risk of burnout among teachers (Kemper et al., 2015; Meiklejohn et al., 2012; Montero-Marin et al., 2015; Olson et al., 2015). There were no outliers included in the data results. The data were tested to make sure all the variables were normally distributed and that nonlinearity did not exist for high reliability and for homoscedasticity to avoid Type I and Type II errors (Osborne \& Waters, 2002). Because of the multiple analysis performed, a Bonferroni correction was made to reflect alpha levels of less than .033.

Research Question 1 (RQ1): What is the relationship between using mindfulness techniques and resilience in high school teachers?

The data collected for RQ 1 were analyzed using correlation analysis to examine if mindfulness significantly predicts resilience. There were eight primary study variables in the Pearson intercorrelations. Among the resulting 28 correlations, all but one was significant at the $\mathrm{p}<.05$ level. The sizes of the coefficients ranged from $\mathrm{r}=.10$ to $\mathrm{r}=.73$ with the median-sized coefficient to being $\mathrm{r}=.42$. The three largest correlations were between total mindfulness with a) describing $(\mathrm{r}=.72, \mathrm{p}<.001)$; $\mathrm{b})$ nonjudging of inner experience $(\mathrm{r}=.70, \mathrm{p}$ $<$.001); and c) nonreactivity to inner experience $(\mathrm{r}=.73, \mathrm{p}<.001)$. This combination of findings provided support to reject null hypothesis 1 and retain alternative hypothesis 1 . Specifically, the total mindfulness score, as well as all five-facet scores, had significant positive correlations with resilience. All these correlations were significant at the $\mathrm{p}<.001$ level.

Research Question 2 (RQ2): How does conscientiousness moderate the relationship between using mindfulness techniques and resilience in high school teachers?

The data collected for RQ 2 were analyzed using multiple regression. The relationship between using mindfulness techniques and resilience as moderated by conscientiousness was displayed with a multiple regression analysis. No multicollinearity was evident based on the variance inflation factors in the model. The three assumption plots (residual histogram, residual P-P plots, a scatterplot of regression standardized residuals against the regression standardized predicted values) were created for this model, and we found that the assumptions of normality homoscedasticity and linearity were adequately met. The regression model predicting resilience based on the total mindfulness score and all five facets of mindfulness moderated by 
conscientiousness positively related to resilience and significant at the $\mathrm{p}=.001$. This means that higher levels of resilience were related to higher total mindfulness and higher conscientiousness scores. The results suggested that conscientiousness, while positively related to resilience, does not act as a moderator of the relationship between resilience and any of the five facets of mindfulness.

Survey data from 133 high school teachers were used to examine the relationship between mindfulness techniques and resilience in high school teachers. Additionally, the data were used to examine if the personality trait conscientiousness moderates the relationship between the use of mindfulness techniques and resilience in high school teachers. The results from RQ1 revealed a significant relationship between mindfulness techniques and resilience in high school teachers. These results indicated a rejection of the null hypothesis 1 . The results from RQ2 revealed that conscientiousness does not significantly moderate the relationship between mindfulness techniques and resilience in high school teachers; therefore, the null hypothesis failed to be rejected.

\section{Discussion}

Burnout is a continuing factor among teachers that needs resolution (Flook et al., 2013; McCarthy et al., 2009; McCormick \& Barnett, 2011). The learning environment is essential to the success of education for students. This study was conducted to fill a gap in understanding whether mindfulness techniques along with high levels of conscientiousness and resilience may help teachers lower the risk of burnout and be better equipped to deal with the demands of their profession. Data were collected using four Likert-type scale surveys distributed to high school teachers at three different schools. Data were analyzed in SPSS using multiple regression. The use of mindfulness techniques was found to significantly predict resilience in high school teachers. However, the personality trait, conscientiousness, was not found to significantly moderate the relationship between mindfulness techniques and resilience in high school teachers.

To analyze the data for RQ 1, we used correlation analysis to examine the relationship between mindfulness techniques and resilience in high school teachers. There was a significant relationship between mindfulness techniques and resilience in high school teachers. Additionally, conscientiousness had significant positive correlations with five of the six mindfulness scores. The findings relative to the relationship between mindfulness and resilience among teachers align with those in the literature regarding the relationship between these two factors in the general workplace setting and healthcare environments. Research has shown that the practice of mindfulness helps in developing resilience (Pierotti \& Remer, 2017) and provides opportunities for individuals to create resilience (Choi \& Tobias, 2015). These outcomes are valuable in increasingly complex and chaotic environments with numerous contradictions (Choi \& Tobias, 2015), such as the ones that teachers encounter in public high schools. Using mindfulness practices, teachers can intentionally maintain awareness of their inner experiences while navigating the complexities of the external environment (Pierotti \& Remer, 2017), thereby developing resilience that can decrease the risk of burnout. In addition to reducing burnout risk, resilience can protect teachers' health and well-being. For instance, research on hospital staff has shown that mindfulness, which was positively related to higher resilience, contributed to lower burnout as well as protected their health and well-being (Olson et al., 2015). Consistent with these conclusions, the findings of this study have significant implications for teacher professional development, both preservice and in-service. By training preservice and in-service teachers in techniques for developing mindfulness, educators of future teachers and school administrators can address the problem of burnout, which contributes to increased healthcare costs, absenteeism, and turnover rates of teachers (Jennings et al., 2017; Roeser et al., 2012).

To analyze the data for RQ 2, we used multiple regression analysis to test the hypothesis of conscientiousness moderating the relationship between mindfulness techniques and resilience in high school teachers, but there 
was no significant relationship. However, previous researchers such as De Vibe et al. (2015) found that mindfulness had more influence on those participants with high scores on the personality trait of conscientiousness. One possible explanation for this variance in findings is the difference in data collection methods. In comparison to De Vibe et al.'s study, where data were collected before and after a mindfulness intervention, this study involved a cross-sectional design whereby data were collected at one point in time with a self-report questionnaire. Another possible explanation concerns the studies' different populations and samples. De Vibe et al. gathered data from first- and second-year medical and psychology students, whereas this present study's sample was high school teachers. Moreover, this study's findings differed from those of Sesker et al. (2016), who suggested that high levels of conscientiousness are related to better stress resilience. Sesker et al.'s sample was comprised primarily of females, whereas this present study's sample included both male and female participants. Additionally, this study used mindfulness, conscientiousness, and resilience as variables, but Sesker et al. used only mindfulness and conscientiousness. The presence of the variable, resilience, in the present study might have affected the findings. This study's findings relative to RQ 2 extend knowledge regarding how conscientiousness moderates the relationship between mindfulness techniques and resilience in high school teachers.

According to the S-ART framework, mindfulness helps in the development of individuals' self-awareness, behavior management, and doing things for the benefit of other people (Vago \& Silbersweig, 2012). The SART framework is a practical way to improve self-awareness about an individual's routine of thought and actions as it relates to other people (Vago, 2014; Vago \& Silbersweig, 2012). As applied to this study, the SART framework was expected to support that mindfulness predicted resilience levels. Our findings supported the theoretical framework of this study, revealing a positive and significant relationship between mindfulness techniques and resilience levels. Total mindfulness had a moderate relationship with resilience levels.

The generalizability of this study was limited to high school teachers. There is a need to examine the use of mindfulness techniques on teacher resilience as moderated by conscientiousness with all teachers. This study's findings did not include all teacher levels and data were collected on a volunteer basis. Therefore, there might be some variation between high school teachers who completed the survey and those who chose not to complete the survey. Any conclusion based on the subscale depersonalization should be interpreted with caution.

It is important to continue to examine mindfulness in the workplace with teachers to prevent costly turnover rates in schools and reduce burnout among teachers. Future research should include all teachers. Additional research should take into consideration the psychological state of individuals when selecting a framework such as biological (health), social (mentors, support system, group dynamics, organizational culture), and religious (sense of hope). Research on additional variables as predictors of the relationship between mindfulness and resilience is important for adding to the literature. Future studies could examine how variables are related in a nonlinear relationship. The quantitative approach for this study did not take into consideration the subtle differences that are important to teachers. Therefore, options for future studies could include exploring the experiences of high school teachers with mindfulness techniques using a qualitative method.

\section{Implications for Practice}

The results of this study may be beneficial in creating a positive social and academic environment for students as well as teachers. The learning environment is important to the success of education for students. But the teaching profession requires a "habit of mind"-mindfulness (Roeser et al., 2012). The teaching profession is more likely to experience burnout if teachers' perspective of demands and the method for dealing with them are not in sync (McCarthy et al., 2009). Developing mindfulness could provide teachers with the tools needed 
to manage the demands of their profession. Through consistent use of mindfulness techniques, teachers can increase self-awareness, improve their well-being, and improve work performance.

Industrial-Organizational practitioners (I-O practitioners) can encourage the incorporation of specific mindfulness practices in teacher daily practices. Additionally, I-O practitioners may consider developing a mindfulness toolkit (a list of different mindfulness practices that can be done daily) that teachers can use. I-O practitioners can identify mindfulness practices that both students and teachers can employ. Practitioners working with teachers should consider the stress level experienced daily. Increasing mindfulness-based interactions may reduce stress levels. It may also be helpful to work with administrators to develop mindfulness-based practice regimens or workshops for school personnel. These regimens or workshops might include information derived from the CARE program, which is based on mindfulness techniques that help teachers manage stress and prevent burnout (Jennings et al., 2017). The activities might consist of focused breathing, reflective thinking, and emotional awareness.

As a professional development tool, mindfulness has the potential to help teachers learn how to increase the quality of their classroom interactions. As burnout decreases among teachers, the associated costs with teacher absenteeism, turnover, and health care are likely to reduce. This study helps increase the knowledge of the role of mindfulness in the workplace regarding high school teachers. Additionally, this study provides a greater awareness of the role of mindfulness with regard to burnout, resilience, and conscientiousness.

There has not been much research about mindfulness in the field of I-O psychology. Additionally, there is minimal information about the connection between mindfulness and the personality trait conscientiousness. This study contributes to the growing research about mindfulness in the workplace. Further research should examine and explore the helpfulness of mindfulness with elementary and middle school teachers and compare the effectiveness of mindfulness for each group. Additionally, further research should explore which aspects of mindfulness are most helpful to teachers as well as examine mindfulness-based stress reduction and its relationship to teacher resilience.

\section{Conclusion}

There is a continuous rise in teacher turnover in the United States because of burnout (Jennings et al., 2017; Roeser et al., 2012). Thus, burnout among teachers needs a resolution (Flook et al., 2013; McCarthy et al., 2009; McCormick \& Barnett, 2011). This study addressed the relationship between mindfulness techniques and resilience in high school teachers, as well as the relationship between the use of mindfulness techniques and resilience as moderated by conscientiousness. There is a significant relationship between mindfulness techniques and resilience in high school teachers, but conscientiousness did not significantly moderate the relationship between mindfulness techniques and resilience in high school teachers. Although conscientiousness does not moderate the relationship between mindfulness techniques and resilience in high school teachers, conscientiousness has a positive relationship with resilience.

Mindfulness helps individuals be intentional about being in the present moment. Constant awareness and attentiveness open the door for creating resilience. Mindfulness provides the opportunity for individuals to look at stressful events as challenges versus threats. Mindfulness can help high school teachers create safe, effective, and nurturing classrooms. The use of mindfulness consistently creates an opportunity for high school teachers to develop their resilience. With high school teachers' resilience development, the risk of burnout decreases. As the risk of burnout decreases, healthcare costs, absenteeism, and turnover rates of teachers can decrease as well. 


\section{References}

Aguado J., Luciano, J. V., Cebolla, A., Serrano-Blanco, A., Soler, J., \& García-Campayo, J. (2015). Bifactor analysis and construct validity of the five-facet mindfulness questionnaire (FFMQ) in non-clinical Spanish samples. Frontiers in Psychology, 6, 404. https://doi.org/10.3389/fpsyg.2015.00404

Aikens, K. A., Astin, J., Pelletier, K. R., Levanovich, K., Baase, C. M., Park, Y. Y., \& Bodnar, C. M. (2014). Mindfulness goes to work: Impact of an online workplace intervention. Journal of Occupational and Environmental Medicine, 56(7), 721-731. https://doi.org/10.1097/JOM.0000000000000209

Arcelay-Rojas, Y. A. (2019). Exploring Puerto Rican preservice teachers' resilience: A focus group study. Journal of Educational Research and Practice, 9(1), 369-385. https://doi.org/10.5590/JERAP.2019.09.1.26

Baer, R. A., Smith, G. T., Hopkins, J., Krietemeyer, J., \& Toney, L. (2006). Using self-report assessment methods to explore facets of mindfulness. Assessment, 13(1), 27-45. https://doi.org/10.1177/1073191105283504

Baer, R. A., Smith, G. T., Lykins, E., Button, D., Krietemeyer, J., Sauer, S., Walsh, E., Duggan, D., \& Williams, J. M. G. (2008). Construct validity of the five-facet mindfulness questionnaire in meditating and nonmeditating samples. Assessment, 15(3), 329-342. https://doi.org/10.1177/1073191107313003

Barrick, M. R., \& Mount, M. K. (1991). The big five personality dimensions and job performance: A meta-analysis. Personnel Psychology, 44(1), 1-26. https://doi.org/10.1111/j.17446570.1991.tboo688.x

Bernay, R. S. (2014). Mindfulness and the beginning teacher. Australian Journal of Teacher Education, 39(7), 58-69. https://doi.org/10.14221/ajte.2014v39n7.6

Brown, K. W., \& Ryan, R. M. (2003). The benefits of being present: Mindfulness and its role in psychological well-being. Journal of Personality and Social Psychology, 84, 822-848. https://doi.org/10.1037/0022-3514.84.4.822

Campbell-Sills, L., \& Stein, M. B. (2007). Psychometric analysis and refinement of the Connor-Davidson resilience scale (CDRISC): Validation of a 10-item measure of resilience. Journal of Traumatic Stress, 2O(6), 1019-1028. https://doi.org/10.1002/jts.20271

Choi, E., \& Tobias, J. (2015). Mind the gap: The link between mindfulness and performance at work needs more attention. Industrial and Organizational Psychology: Perspectives on Science and Practice, 8(4), 629-633. https://doi.org/10.1017/iop.2015.90

Connor, K. M., \& Davidson, J. R. T. (2003), Development of a new resilience scale: The ConnorDavidson Resilience Scale (CD-RISC). Depression \& Anxiety, 18, 76-82. https://doi.org/10.1002/da.10113

Crescentini, C., \& Capurso, V. (2015.) Mindfulness meditation and explicit and implicit indicators of personality and self-concept changes. Frontiers in Psychology, 6(44). https://doi.org/10.3389/fpsyg.2015.00044

de Bruin, E. I., Topper, M., Muskens, J. M., Bögels, S. M., \& Kamphuis, J. H. (2012). Psychometric properties of the Five Facets Mindfulness Questionnaire (FFMQ) in a meditating and a nonmeditating sample. Assessment, 9(2), 187-197. https://doi.org/10.1177/1073191112446654

De Vibe, M., Solhaug, I., Tyssen, R., Friborg, O., Rosenvinge, J. H., Sørlie, T., Halland, E., \& Bjørndal, A. (2015). Does personality moderate the effects of mindfulness training for medical and psychology students? Mindfulness, 6(2), 281-289. https://doi.org/10.1007/s12671-013-0258-y 
Digman, J. M. (1990). Personality structure: Emergence of the five-factor model. Annual Review of Psychology, 41(1), 417-440. https://doi.org/10.1146/annurev.psych.41.1.417

Flook, L., Goldberg, S. B., Pinger, L., Bonus, K., \& Davidson, R. J. (2013). Mindfulness for teachers: A pilot study to assess effects on stress, burnout and teaching efficacy. Mind, Brain and Education, 7(3), 182-195. https://doi.org/10.1111/mbe.12026

George, J. M., \& Zhou, J. (2001). When openness to experience and conscientiousness are related to creative behavior: An interactional approach. Journal of Applied Psychology, 86(3), 513-524. https://doi.org/10.1037/0021-9010.86.3.513

Giluk, T. L. (2009). Mindfulness, Big Five personality, and affect: A meta-analysis. Personality and Individual Differences, 47(8), 805-811. https://doi.org/10.1016/j.paid.2009.06.026

Good, D. J., Lyddy, C. J., Glomb, T. M., Bono, J. E., Brown, K. W., Duffy, M. K., Baer, R. A., Brewer, J. A., \& Lazar, S. W. (2016). Contemplating mindfulness at work: An integrative review. Journal of Management, 42(1), 114-142. https://doi.org/10.1177/0149206315617003

Goldberg, L. R. (1999). A broad-bandwidth, public domain, personality inventory measuring the lower-level facets of several five-factor models. Personality Psychology in Europe, 7(1), 7-28.

Goldberg, L. R., Johnson, J. A., Eber, H. W., Hogan, R., Ashton, M. C., Cloninger, C. R., \& Gough, H. G. (2006). The international personality item pool and the future of public-domain personality measures. Journal of Research in Personality, 4O(1), 84-96. https://doi.org/10.1016/j.jrp.2005.08.007

Jennings, P. A., Brown, J. L., Frank, J. L., Doyle, S., Oh, Y., Davis, R., Rasheed, D., DeWeese, A., DeMauro, A., Cham, H., \& Greenberg, M. T. (2017). Impacts of the CARE for teachers' program on teachers' social and emotional competence and classroom interactions. Journal of Educational Psychology, 1-19. https://doi.org/10.1037/eduoooo187

Jennings, P. A., Frank, J. L., Snowberg, K. E., Coccia, M. A., \& Greenberg, M. T. (2013). Improving classroom learning environments by Cultivating Awareness and Resilience in Education (CARE): Results of a randomized controlled trial. School Psychology Quarterly, 28(4), 374. https://doi.org/10.1037/spq0000035

Kabat-Zinn, J. (2012). Mindfulness for beginners: Reclaiming the present moment-and your life [Audiobook]. Sounds True, Inc. https://bit.ly/2POj2NG

Kemper, K. J., Mo, X., \& Khayat, R. (2015). Are mindfulness and self-compassion associated with sleep and resilience in health professionals? The Journal of Alternative and Complementary Medicine, 21(8), 496-503. https://doi.org/10.1089/acm.2014.0281

Kokkinos, C. M. (2006). Factor structure and psychometric properties of the Maslach Burnout InventoryEducators Survey among elementary and secondary school teachers in Cyprus. Stress and Health, 22, 25-33. https://doi.org/10.1002/smi.1079

Latzman, R. D., \& Masuda, A. (2013). Examining mindfulness and psychological inflexibility within the framework of Big Five personality. Personality and Individual Differences, 55(2), 129-134. https://doi.org/10.1016/j.paid.2013.02.019

Ledesma, J. (2014). Conceptual frameworks and research models on resilience in leadership. Sage Open, 4(3), 1-8. https://doi.org/10.1177/2158244014545464

Lee, K., \& Bowen, S. (2014). Relation between personality traits and mindfulness following mindfulnessbased training: A study of incarcerated individuals with drug abuse disorders in Taiwan. International Journal of Mental Health and Addiction, 13(3), 413-421. https://doi.org/10.1007/s11469-014-9533-y 
Leiter, M. P., \& Maslach, C. (2016). Latent burnout profiles: A new approach to understanding the burnout experience. Burnout Research, 3(4), 89-100. https://doi.org/10.1016/j.burn.2016.09.001

Mansfield, C. F., Beltman, S., Price, A., \& McConney, A. (2012). Don't sweat the small stuff: Understanding teacher resilience at the chalkface. Teaching \& Teacher Education, 28(3), 357-367. https://doi.org/10.1016/j.tate.2011.11.001

Marianetti, O., \& Passmore, J. (2012). Mindfulness at work: Paying attention to enhance well-being and performance. Oxford Handbook of Positive Psychology and Work. https://doi.org/10.1093/oxfordhb/9780195335446.013.0015

Marx, R., \& Jones, F. (2017). The path of mindfulness: An NHS case example. Healthcare Counselling \& Psychotherapy Journal, 17(2), 18-21. http://create.canterbury.ac.uk/15576/

Maslach, C. (1998). A multidimensional theory of burnout. Theories of Organizational Stress, 68. https://www.researchgate.net/publication/280939428_A_Multidimensional_Theory_of_Burnout

Maslach, C., Jackson, S. E., \& Leiter, M. P. (1996). Maslach Burnout Inventory (3rd ed.). Consulting Psychologists Press. https://www.researchgate.net/profile/Christina_Maslach

Maslach, C., Jackson, Susan E., \& Schwab, R. (2019). MBI: Educators survey. Mind Garden. https://www.mindgarden.com/316-mbi-educators-survey

Maslach, C., Schaufeli, W. B., \& Marek, T. (1993). Historical and conceptual development of burnout. Professional Burnout: Recent Developments in Theory and Research, 1-16.

Maslach, C., Schaufeli, W. B., \& Leiter, M. P. (2001). Job burnout. Annual Review of Psychology, 52(1), 397-422. https://doi.org/10.1146/annurev.psych.52.1.397

McCarthy, C. J., Lambert, R. G., O’Donnell, M., \& Melendres, L. T. (2009). The relation of elementary teachers' experience, stress, and coping resources to burnout symptoms. Elementary School Journal, 109(3), 282-300. https://doi.org/10.1086/592308

McCormick, J., \& Barnett, K. (2011). Teachers' attributions for stress and their relationships with burnout. The International Journal of Educational Management, 25(3), 278-293, https://doi.org/10.1108/09513541111120114

Meiklejohn, J., Phillips, C., Freedman, M. L., Griffin, M. L., Biegel, G., Roach, A., Frank, J., Burke, C., Pinger, L., Soloway, G., Isberg, R., Sibinga, E., Grossman, L., \& Saltzman, A. (2012). Integrating mindfulness training into $\mathrm{K}-12$ education: Fostering the resilience of teachers and students. Mindfulness, 3(4), 291-307. https://doi.org/10.1007/s12671-012-0094-5

Montero-Marin, J., Tops, M., Manzanera, R., Demarzo, M. M. P., de Mon, M. Á., \& García-Campayo, J. (2015). Mindfulness, resilience, and burnout subtypes in primary care physicians: The possible mediating role of positive and negative affect. Frontiers in psychology, 6. https://doi.org/10.3389/fpsyg.2015.01895

Napoli, M. (2004). Mindfulness training for teachers: A pilot program. Complementary Health Practice Review, 9(1), 31-42. https://doi.org/10.1177/1076167503253435

Nhất Hạnh, T. (1987). The miracle of mindfulness: An introduction to the practice of meditation. Beacon Press.

Olson, K., Kemper, K. J., \& Mahan, J. D. (2015). What factors promote resilience and protect against burnout in first-year pediatric and medicine-pediatric residents? Journal of Evidence-Based Complementary \& Alternative Medicine, 20(3), 192-198. https://doi.org/10.1177/2156587214568894 
Osborne, J., \& Waters, E. (2002). Four assumptions of multiple regression that researchers should always test. Practical Assessment, Research \& Evaluation, 8(2). https://scholarworks.umass.edu/pare/vol8/iss1/2/

Piatkowska, J. M. (2014). The relationship between mindfulness and burnout among Master of Social Work students [Doctoral dissertation]. Portland State University. PDXScholar. https://doi.org/10.15760/etd.1961

Pierotti, D., \& Remer, R. (2017). Cultivating resilience through mindful caregiving: The continuing legacy of Zen Hospice Project. Home Healthcare Now, 35(5), 290-291. https://doi.org/10.1097/NHH.0000000000000536

Purser, R. E., \& Milillo, J. (2015). Mindfulness revisited: A Buddhist-based conceptualization. Journal of Management Inquiry, 24(1), 3-24. https://doi.org/:10.1177/1056492614532315

Richardson, G. E. (2002). The metatheory of resilience and resiliency. Journal of Clinical Psychology, 58(3), 307-321. https://doi.org/10.1002/jclp.10020

Roberts, B. W., Chernyshenko, O. S., Stark, S., \& Goldberg, L. R. (2005). The structure of conscientiousness: An empirical investigation based on seven major personality questionnaires. Personnel Psychology, 58(1), 103-139. https://doi.org/10.1111/j.1744- 6570.2005.00301.x

Roberts, B. W., Lejuez, C., Krueger, R. F., Richards, J. M., \& Hill, P. L. (2014). What is conscientiousness and how can it be assessed? Developmental Psychology, 5O(5), 1315-1330. https://doi.org/10.1037/a0031109

Roeser, R., Skinner, E., Beers, J., \& Jennings, P. (2012). Mindfulness training and teachers' professional development: An emerging area of research and practice. Child Development Perspectives, 6(2), 167-173. https://doi.org/10.1111/j.1750-8606.2012.00238.x

Sesker, A. A., Súilleabháin, P. Ó., Howard, S., \& Hughes, B. M. (2016). Conscientiousness and mindfulness in midlife coping: An assessment based on MIDUS II. Personality and Mental Health, 1O(1), 2942. https://doi.org/10.1002/pmh.1323

Siegling, A. B., \& Petrides, K. V. (2014). Measures of trait mindfulness: Convergent validity, shared dimensionality, and linkages to the five-factor model. Frontiers in Psychology, 5. https://doi.org/10.3389/fpsyg.2014.01164

Sutcliffe, K. M., Vogus, T. J., \& Dane, E. (2016). Mindfulness in organizations: A cross-level review. Annual Review of Organizational Psychology and Organizational Behavior, 355-381. https://doi.org/10.1146/annurev-orgpsych-041015-062531

Topolewska, E., Skimina, E., Strus, W., Cieciuch, J., \& Rowiński, T. (2017). The short IPIP-BFM-20 questionnaire for measuring the Big Five. Roczniki Psychologiczne/Annals of Psychology, 17(2), 385-402.

Vago, D. R. (2014). Mapping modalities of self-awareness in mindfulness practice: A potential mechanism for clarifying habits of mind. Annals of the New York Academy of Sciences, 1307(1), 28-42. https://doi.org/10.1111/nyas.12270

Vago, D. R., \& Silbersweig, D. A. (2012). Self-awareness, self-regulation, and self-transcendence (S-ART): A framework for understanding the neurobiological mechanisms of mindfulness. Frontiers in Human Neuroscience, 6, 296. https://doi.org/10.3389/fnhum.2012.00296

Vogt, W. P. (2011). SAGE quantitative research methods. SAGE Publications Ltd. https://doi.org/10.4135/9780857028228 
Yates, T. M., \& Masten, A. S. (2004). Fostering the future: Resilience theory and the practice of positive psychology. In P. A. Linley and S. Joseph (Eds.), Positive psychology in practice (pp. 521-539). John Wiley \& Sons, Inc. https://doi.org/10.1002/9780470939338.ch32

Williams, M. J., Dalgleish, T., Karl, A., \& Kuyken, W. (2014). Examining the factor structures of the Five Facet Mindfulness Questionnaire and the Self-Compassion Scale. Psychological Assessment, 26(2), 407-418. https://doi.org/10.1037/a0035566 about developments and change in the field of education and learning. The journal includes research and related content that examine current relevant educational issues and processes. The aim is to provide readers with knowledge and with strategies to use that knowledge in educational or learning environments. JERAP focuses on education at all levels and in any setting, and includes peer-reviewed research reports, commentaries, book reviews, interviews of prominent individuals, and reports about educational practice. The journal is sponsored by The Richard W. Riley College of Education and Leadership at Walden University, and publication in JERAP is always free to authors and readers. 